\title{
Child Personality as Moderator of Outcome in a School-based Intervention for Preventing Externalising Behaviour
}

\author{
SABINE STOLTZ ${ }^{1 *}$, PETER PRINZIE ${ }^{1}$, AMARANTA DE HAAN ${ }^{2}$, MONIOUE VAN LONDEN $^{1}$, \\ BRAM OROBIO DE CASTRO ${ }^{3}$ and MAJA DEKOVIĆ \\ ${ }^{1}$ Utrecht University, Research Centre Psychosocial Development in Context, The Netherlands \\ ${ }^{2}$ Ghent University, Department of Developmental, Personality, and Social, Psychology, Belgium \\ ${ }^{3}$ Utrecht University, Department of Developmental Psychology, The Netherlands
}

\begin{abstract}
Studying moderators of intervention effects is essential to elucidate what works for whom. The present study investigated whether child personality moderates short-term and follow-up effects of an individualised preventive school-based intervention for children with externalising behaviour. The sample consisted of 48 schools, with 264 fourth-grade children displaying externalising behaviour $\left(M_{\text {age }}=10.2\right.$ years $)$, randomly assigned to the intervention $(n=191)$ or no intervention control $(n=73)$ condition. Teachers and children reported at pretest, posttest and follow-up test about reactive and proactive aggression. Child personality was assessed by teachers at pretest. Child conscientiousness moderated short-term intervention effects, indicating that more organised and planful children benefited more from the intervention. Child extraversion moderated both short-term and follow-up intervention effects, with low extraverted children showing larger effects. These results affirm the importance of including personality as moderator of intervention effects in future studies, as interventions adapted to specific child traits might yield larger effects. Copyright (C) 2012 John Wiley \& Sons, Ltd.
\end{abstract}

Key words: personality; intervention; reactive and proactive aggression; moderation

Pervasive and unremitting aggressive behaviour at school age is a significant risk factor for future difficulties such as peer rejection, school failure, drug abuse and delinquency in adolescence (Broidy et al., 2003). Intervening at young age, when behavioural patterns are more easily modified, can prevent children from developing life-course persistent conduct problems (Tremblay, 2006). During the last decade, evidence has been accumulating that school-based preventive child interventions are, in general, moderately effective in reducing aggression (mean effect sizes range from .29 to .35; McCart, Priester, Davies, \& Azen, 2006; Wilson \& Lipsey, 2007). Moreover, an increasing number of studies on the effectiveness of child interventions identified specific child characteristics (e.g. age, gender and ethnicity) that influence (i.e. moderate) intervention effects (e.g. child age; McCart et al., 2006).

Studying moderator effects is important because interventions, for which no (or small) overall effects emerge, may still be effective for subgroups of children (Kraemer, Wilson, Fairburn, \& Agras, 2002). Identifying children who are differentially responsive to interventions can also enhance clinical practice because selection of children for specific interventions can be more adequate, which in turn can reduce poor treatment response and high drop-out rates (40\%-60\%) in child mental health care (Beauchaine, Webster-Stratton, \& Reid, 2005; La Greca, Silverman, \& Lochman, 2009). Additionally, programmes can be modified and personalised for children for whom standardised interventions are less effective.

*Correspondence to: Sabine Stoltz, Heidelberglaan 1 Postbus 8054, Utrecht 3508 TC, The Netherlands.

E-mail: s.e.m.j.stoltz@uu.nl
Finally, identifying moderators can contribute to developmental theory by elucidating whether developmental processes can be changed under certain conditions (Kellam \& Rebok, 1992).

Intervention studies usually identify moderators that are based on routinely obtained information (Kazdin, 2007), such as age or initial level of problems. However, moderators that are theoretically grounded may be most important to consider. A plausible moderator that has been relatively ignored is child personality. In recent years, the construct of personality has become more influential in theories about the development of behaviour problems (Shiner \& Caspi, 2003). On the basis of the vulnerability or predisposition model, it can be hypothesised that certain personality traits place children at risk for the onset and maintenance of behaviour problems (Tackett, 2006). There is growing consensus that a comprehensive and systematic way to measure personality traits in children is with the Big Five model (McCrae \& Costa, 1999), labelled as follows: extraversion, benevolence (agreeableness in adults), conscientiousness, emotional stability and imagination.

There is empirical evidence that the Big Five is a useful framework for ordering individual findings on child personality (Caspi \& Shiner, 2006), and more specifically, several studies have found that low benevolence, conscientiousness, and emotional stability, and high extraversion in children (aged 6-13 years) were concurrently and longitudinally related to more externalising behaviour (De Haan, Prinzie, \& Deković, 2010; John, Caspi, Robins, Moffitt, \& Stouthamer-Loeber, 1994; Prinzie, van der Sluis, de Haan, \& Deković, 2010; Van den Akker, Deković, \& Prinzie, 2010). Children (non-clinical preschool and elementary school) with externalising behaviours 
are particularly characterised by low benevolence (i.e. selfcentred, hostile, manipulative), low conscientiousness (i.e. lack of ambition, difficult to control impulses) and to a lesser extent high extraversion (Prinzie et al., 2003). Besides, it has been found that differences in personality traits result in differential susceptibility to rearing practices (Belsky, 2005; Prinzie et al., 2003) and may evoke different parenting and peer behaviour (Manders, Scholte, Janssens, \& De Bruyn, 2006; Prinzie et al., 2010). As a result, personality seems to be a predictor for different pathways to behavioural problems, and this may provide important information for intervention studies to identify and target potential vulnerable subgroups (Caspi \& Shiner, 2006; Frick, 2004).

Given this prominence of child Big Five personality characteristics for the development of problem behaviours, there are reasons to speculate that personality traits may also influence (i.e. moderate) the effectiveness of interventions. Although child personality traits have not been evaluated directly in clinical trials, a recent study on personality-targeted interventions for substance use in adolescents indicated that individual differences in personality reflect different susceptibility to substance misuse (Conrod, Castellanos, \& Mackie, 2008). Interventions that focused on personality risk factors (impulsivity, sensation seeking, anxiety sensitivity, negative thinking) in adolescents and young adults were found to be effective in reducing substance use, and strongest effects were found for those personality types associated with higher risk for substance use (Conrod, Castellanos-Ryan, \& Strang, 2010; Conrod, Stewart, Comeau, \& Maclean, 2006; Watt, Stewart, Birch, \& Bernier, 2006). In another recent study (Hawes \& Dadds, 2005) on treatment effects for six-year old boys referred for conduct problems, it was found that callous-unemotional traits (i.e. limited empathy and guilt, constricted emotionality) in treated children were associated with poorer treatment outcomes. Although not really a personality trait, callous-unemotional traits can be considered as a personality-relevant concept. These results indicate that personality is important to consider as moderator of direct intervention effects.

Although considerable evidence exists for specific child personality traits that predict later externalising behaviour (e.g. Tackett, 2006), to our knowledge, the effects of personality on intervention outcomes in children with externalising behaviour problems have rarely been examined. Additionally, personality could even impact longer-term effects of interventions on child externalising behaviour. Although many school-based interventions have shown significant initial effects on child's externalising behaviour, findings on follow-up are mixed. Therefore, understanding factors that might be particularly influential in follow-up effects of promising interventions is needed; however, these factors are relatively understudied (Kellam \& Rebok, 1992). For example, it is possible that for more conscientious children, an intervention will lead to maintenance of initial effects on externalising behaviour because these children are better able to control their impulses and are more motivated to carry out tasks that they learned during the intervention.

Given the lack of intervention studies that include personality as moderator for children with externalising behaviour, we formed hypotheses based on prior findings and theory about relations between personality and externalising behaviour. On the basis of previous work (Miller \& Lynam, 2001; Prinzie et al., 2010; Tackett, 2006), children who are low on benevolence and conscientiousness and high on extraversion are expected to show less beneficial outcomes. These traits have the strongest link with externalising behaviour. Externalising behaviour of children with these traits therefore may be more difficult to change, perhaps because these children are less susceptible to environmental influences (e.g. Prinzie et al., 2003). For example, highly conscientious children, who are organised and practical, possibly benefit more from interventions, as they are better able to do things according to a plan. On the other hand, low benevolent children likely have stronger believes that aggressive responses will lead to positive outcomes (Miller \& Lynam, 2001). These cognitions might be less sensitive to change, and therefore, their externalising behaviour might be more stable. Highly extravert children are less inhibited and have elevated activity levels (Tackett, 2006). When these children are provocated by peers, which is underlying of (reactive) aggression (Dodge \& Coie, 1987), they may respond impulsively with aggression, without considering their newly learned skills.

In sum, the aim of the present study is to examine the moderating role of child personality on immediate and followup effects of a preventive intervention, Stay Cool Kids, for elementary school children with externalising behaviour. Stay Cool Kids is an indicated-type school-based intervention, delivered by trained professionals on an individual basis that still involves the context. It is based on a social cognitive perspective on the development of aggressive behaviour problems (Crick \& Dodge, 1994; Lemerise \& Arsenio, 2000). The main outcomes are reported by Stoltz et al. (2012): Moderate intervention effects were found on multiple child, parent and teacher outcomes including reactive and proactive aggression, social cognitive functioning, selfperception and clinically relevant changes on externalising behaviour. Even though the intervention is found to be effective, there is considerable variability in outcomes. Therefore, we conducted analyses following up from the main effectiveness study to explore personality as moderator of outcomes within an effectiveness trial. Moreover, by including information obtained from teachers regarding child personality and from children regarding their reactive and proactive aggression, rater bias was avoided. Teachers have been found to be accurate raters of child personality because of their expertise on normative child development and their experience with a broad range of children (Goldberg, 2001; Prinzie \& Deković, 2008).

\section{METHOD}

\section{Design}

A randomised controlled trial design was used to evaluate intervention effects. Forty-eight elementary schools, in two urban regions in the Netherlands, were randomly assigned to the intervention or control condition. Each school (fourth-grade classes) participated in the intervention condition, as well as in the control condition (Figure 1). In this way, schools were more 


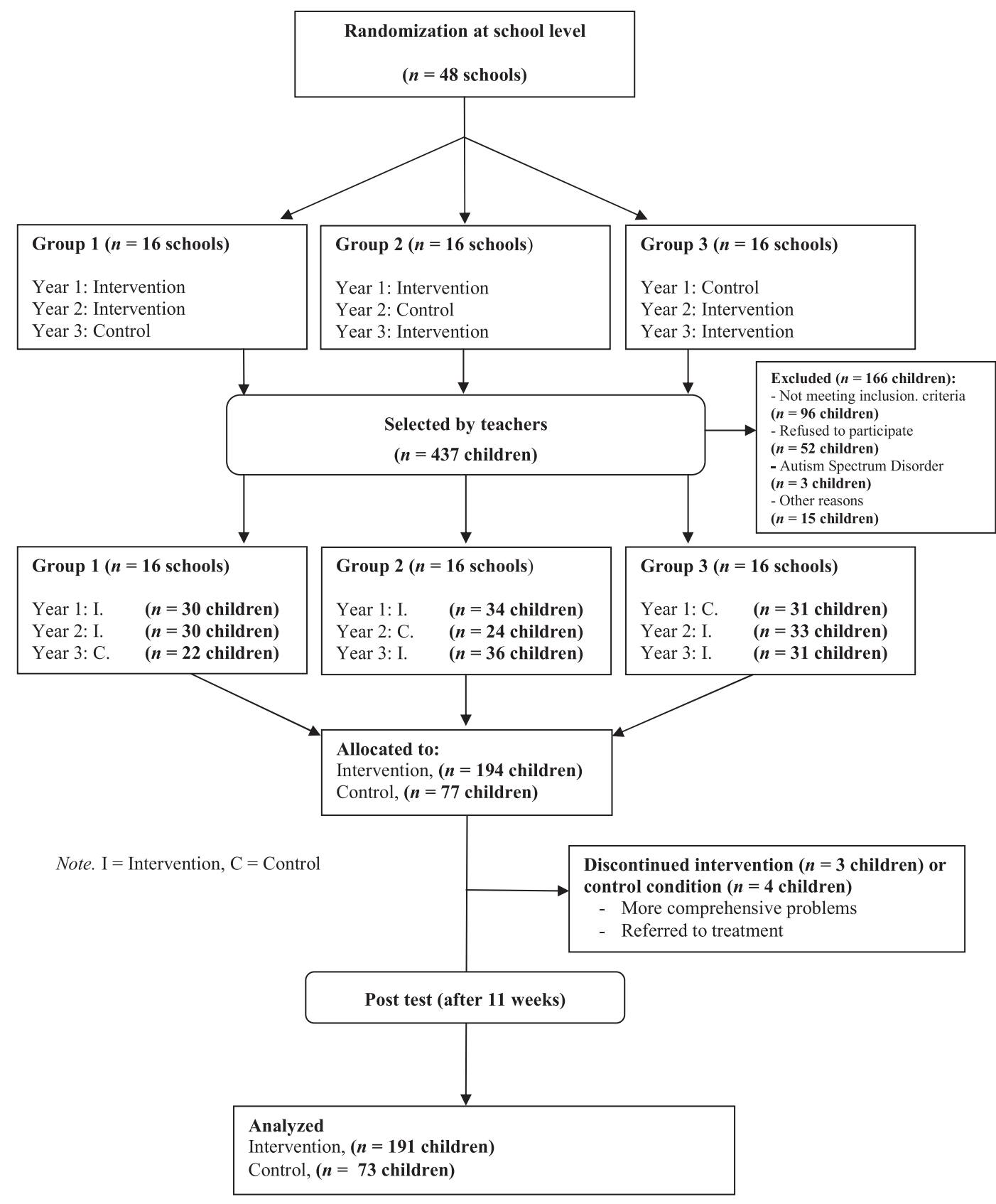

Figure 1. Flow chart of randomisation design.

willing to participate in the control condition and treatment condition was randomised in such a way to ensure that intervention effects could not be due to school factors. However, randomisation at school level could possibly lead to biased results. To examine whether the nesting of children within schools affected results, we computed the design effect (Muthén, 2000). This is expressed as $d=1+\rho(c-1)$, where $\rho$ is the average intraclass correlation (.28) and $c$ is the common cluster size (i.e. average number of children per school, 4.2). The design effect was 1.90 , which is smaller than 2.0 and can therefore be ignored.

There were three assessment periods: prior to the beginning of the intervention, at intervention termination (after 11 weeks) and at six months follow-up when children were in fifth grade. Dependent measures were individually administered to children in their school settings by trained research assistants. Teachers received questionnaires and were asked to return the questionnaires within a week. Both fourth-grade (pretest and posttest) as fifth-grade (follow-up) teachers filled out questionnaires. The study was approved by the Dutch Central Committee on Research Involving Human Subjects.

\section{Participants}

First, parents of all children in fourth grade received a general information letter about the study and a consent form to give permission for teachers to fill out the Teacher Report Form (TRF; age 6-18 years; Achenbach, 1991) about their child. Then, teachers nominated children from their classes with the highest levels of externalising behaviour (the top 30\%) and 
filled out the 32-item externalising scale of the TRF $(n=437)$. Next, researchers selected children based on their $T$-scores. The inclusion criterion was a $T$-score $>60$, indicating a (sub) clinical level of externalising behaviour, which places children at risk for various negative outcomes. Some children did not meet the inclusion criterion of $T$-score $>60(n=96)$, participated in other forms of youth care $(n=15)$ or were diagnosed with autism spectrum disorder $(n=3)$, and some parents refused to participate $(n=52)$. If a child was selected, primary caretakers were contacted by phone and in meetings at school to gather their informed consent to participate in this study. After consent was obtained, the baseline pre-assessment was conducted. Three children discontinued the child intervention, and four children discontinued in the control condition (Figure 1).

The final sample consisted of 264 children ( $72 \%$ boys; $27 \%$ non-Western cultural background) and their teachers $(n=155)$. At posttest, $99 \%$ of the children in the intervention had completed the intervention and filled out the questionnaire $(n=264)$. For 24 children $(9 \%)$, teachers did not complete the questionnaire at posttest. These missing values were completely random (Little's Missing Completely At Random (MCAR) test: $\chi^{2} / 2=.05, p=.95$ ). At follow-up, $95 \%$ of the children filled out the questionnaire and $85 \%$ of the teachers. Reasons for non-completion were parents' refusal to continue with measurement $(n=3)$, moving to other places $(n=5)$ or other reasons $(n=5)$. For these 13 children, teachers did not complete questionnaires either. Other reasons for teachers' missing data $(n=27)$ were lack of time or personal circumstances. Missing data for children (Little's MCAR test: $\chi^{2} /$ $2=2.59, p=.46$ ) and teachers (Little's MCAR test: $\chi^{2} /$ $2=5.54, p=.69$ ) at follow-up were completely random as well. Children with complete and non-complete data did not differ significantly on predictors or demographic characteristics. Multiple imputation is recommended as an efficient missing data handling technique (Baraldi \& Enders, 2010). We used the multiple imputation techniques (LISREL 8.7, Jöreskog \& Sörbom, 1996) with the expected maximisation algorithm. Imputed data were used in further analyses.

There were no significant differences in gender or TRF score for those children and parents who consented to participate and those who did not. Children in the intervention and control group did not differ significantly on demographic characteristics (socioeconomic status, ethnic background). Children in the control condition received care as usual (e.g. remedial teaching, universal remediation programmes), if necessary, within their school.

\section{Intervention 'Stay Cool Kids'}

The Stay Cool Kids training is a social cognitive intervention that focuses on reciprocal relations between cognitions, emotions and behaviour of the child. The training is designed to reduce aggressive behaviour in highly aggressive children at elementary schools. The long-term goal is to prevent the development of disruptive behaviour disorders. We recently reported short-term effects in reducing externalising behaviour problems and changing social cognitive functioning among fourth-grade school children (Stoltz et al., 2012). Trainers from youth mental health care centres $(n=33)$ worked individually, in eight weekly sessions of 45 minutes, with the target child. Children were seen during the school day from January until March. The trainer met with parents and teachers before the start of the training, during a midterm evaluation and at the end of the training.

The training consisted of two phases. In the first phase, trainers investigated child's specific needs and competences. The first session starts with a general introduction. For the second and third sessions, trainers were able to choose exercises, which were best suited for the individual child. After the third session, an individual analysis of child's competences was made and discussed with parents and teachers during a midterm evaluation, resulting in an individual intervention plan. For the intervention plan, trainers chose five from nine programme components, which were most appropriate for the individual child's needs, as described in the trainer manual. Before Phase 2 (Sessions 4-8) started, a contract between the trainer and child was signed, in which the training programme is described. Exercises focused on (i) self-perception (less negative, realistic self-perception), (ii) social cognitions (attribution of benign intent in ambiguous situations, accurate representation of other children emotions), (iii) anger management (emotion-regulations strategies, e.g. 'stop-think-act'), and (iv) aggressive behaviour (generation of less aggressive responses to social provocations). Parents and teachers received information after each training session about what was carried out during the training. Also, they were asked to practice together with the child its newly learned skills. Trainers filled in logs after every intervention session, and these logs indicated that $99 \%$ of the trainings were completed as planned and consisted of eight sessions. The choice of exercises for individual clients did not depend on their personality characteristics, as indicated by non-significant correlations $(r s<.10)$ between exercise logs and personality variables.

\section{Measures}

\section{Aggressive behaviour}

Teachers reported on reactive and proactive aggression with the Teacher Rating of Aggression (TRA; Dodge \& Coie, 1987; Hendrickx, Crombez, Roeyers, \& Orobio de Castro, 2003). Items for reactive (e.g. 'When this child has been teased or threatened, he or she gets angry easily and strikes back'; three items) and proactive aggression (e.g. 'This child uses force to dominate peers'; three items) were rated on a 5-point Likert-scale $(1=$ never to $5=$ always $)$. An adopted child version of the TRA was used to measure child reported reactive and proactive aggression. Reliability, factor structure and validity of the TRA are adequate (e.g. Hendrickx et al., 2003; De Castro, Merk, Koops, Veerman, \& Bosch, 2005). Cronbach's alphas were averaged across pretest, posttest, and follow-up assessments and were as follows. For teachers: reactive $=.85$; proactive $=.85$; children: reactive $=.58$, proactive $=.72$.

Teachers filled in the TRF (age 6-18 years, Achenbach, 1991) to measure aggressive (e.g. 'argues a lot', 20 items) and delinquent behaviour (e.g. 'does not seem to feel guilty after misbehaving', 20 items). Average Cronbach's alphas were .85 for aggressive behaviour and .72 for delinquent behaviour. The TRF is an extensively validated instrument with adequate 
reliability and validity (Achenbach, 1991; Verhulst, van der Ende, \& Koot, 1997).

\section{Personality}

Teachers rated about child personality characteristics using the Hierarchical Personality Inventory for Children (HiPIC, Mervielde \& De Fruyt, 1999). The HiPIC is a comprehensive personality inventory that assesses individual differences of children in 144 items. It has been shown to have high convergent and discriminate validities, temporal stability and replicability (Mervielde \& De Fruyt, 2002; Shiner \& Caspi, 2003). The items are on a 5-point scale, ranging from $1=$ almost not characteristic to $5=$ very characteristic (e.g. 'accepts authority'). Number of items and Cronbach's alphas for each dimension were extraversion (32 items, .92) benevolence (46 items, .85), conscientiousness (32 items, .93), emotional stability (16 items, .87) and imagination (24 items, .93).

\section{Plan of analyses}

To test whether personality is differentially associated with outcomes for the intervention group compared with the control group, interaction effects need to be examined (Gardner, Hutchings, Bywater, \& Whitaker, 2010; Hinshaw, 2002; Kraemer et al., 2002). We performed a series of analyses of covariance (ANCOVA), using general linear models to test whether personality moderates the effects. We started with testing short-term and follow-up intervention effects with pretest scores as covariate and intervention status $(0=$ control group $; 1=$ intervention group $)$ as fixed factor. Effect sizes were calculated as the standardised mean difference with mean gain scores (Lipsey \& Wilson, 2001). Effect sizes of $.20, .50$ and .80 were considered as small, moderate and large, respectively (Cohen, 1988).

Next, to test for moderation at posttest and follow-up, pretest scores were entered as covariate; intervention status and personality traits (separately) were entered as fixed factors, and interactions with intervention status were tested. Because we expected extremes on the dimensions, we created subgroups for each particular personality trait based on mean \pm one $S D$ $(1=$ low, $2=$ middle, $3=$ high $)$. A significant interaction effect suggests moderation, because it indicates that the effect of the intervention differs for separate values of the moderator (Baron \& Kenny, 1986). Significant moderator effects were further explored by testing intervention effects for separate subgroups of personality. Effect sizes were calculated.

\section{RESULTS}

\section{Preliminary analyses}

Table 1 shows correlations between personality dimensions and aggression at pretest. Extraversion, benevolence, conscientiousness, emotional stability and imagination were related to teacher reported aggressive (reactive and proactive) and delinquent behaviour. Higher scores on these personality traits were related to lower levels of aggressive or delinquent behaviour at baseline. Higher levels of imagination were related to less child reported aggression.

\section{Short-term and follow-up intervention effects}

Table 2 shows means and standard deviations of outcomes at pretest, posttest, and follow-up-test and effect sizes. First, intervention effects were tested at posttest, controlling for pretest scores. For child reported reactive $(F(2,263)=4.06, p=.02)$ and proactive aggression $(F(2,263)=8.02, p<.001)$ significant effects were found, indicating that the intervention reduced levels of aggression at posttest. For teacher reported reactive aggression, intervention effects were also significant $(F(2,263)=3.81, p=.02)$. In addition, the intervention significantly reduced teacher reported aggressive $(F(2,263)=7.27$, $p<.001)$ but not delinquent behaviour. No significant intervention effects were found for teacher reported proactive aggression.

Next, to examine whether beneficial Stay Cool Kids effects were maintained at follow-up, we performed ANCOVAs, controlling for pretest scores. Beneficial effects that were found at posttest remained for two outcomes: Teacher reported reactive aggression $(F(2,263)=5.65, p=.00)$ and teacher reported aggressive behaviour $(F(2,263)=5.40, p=.01)$.

\section{Moderator of intervention effects}

To investigate whether intervention effects at posttest were moderated by personality, ANCOVAs with pretest scores as covariate and interactions (personality factor $\times$ intervention status) were performed. We conducted a separate ANCOVA

Table 1. Correlations personality and externalising behaviour pretest

\begin{tabular}{|c|c|c|c|c|c|}
\hline Outcome & Extraversion & Benevolence & Conscientiousness & Emotional stability & Imagination \\
\hline Reactive aggression $\mathrm{T}$ & $-.14^{*}$ & $-.31 * *$ & -.09 & -.11 & -.12 \\
\hline Proactive aggression $\mathrm{T}$ & -.07 & $-.30 * *$ & $-.13 * *$ & .06 & $-.17 * *$ \\
\hline Aggressive behaviour $\mathrm{T}$ & .00 & $-.43 * *$ & $-.16 *$ & $-.14^{*}$ & -.05 \\
\hline Delinquent behaviour $\mathrm{T}$ & -.06 & $-.31 * *$ & $-.29 * *$ & .08 & $-.23 * *$ \\
\hline Reactive aggression $\mathrm{C}$ & .06 & -.06 & -.11 & .07 & $-.13 *$ \\
\hline Proactive aggression $\mathrm{C}$ & -.00 & -.06 & -.03 & .05 & -.09 \\
\hline
\end{tabular}

Note:

$\mathrm{T}$, teacher report; $\mathrm{C}$, child report.

$* p<.05$.

$* * p<.01$ 
Table 2. Means, standard deviations and effect sizes

\begin{tabular}{|c|c|c|c|c|c|c|c|c|}
\hline \multirow[b]{2}{*}{ Outcome } & \multicolumn{3}{|c|}{ Intervention } & \multicolumn{3}{|c|}{ Control group } & \multirow{2}{*}{$\begin{array}{l}\text { Effect size } \\
\text { pretest to } \\
\text { posttest }\end{array}$} & \multirow{2}{*}{$\begin{array}{l}\text { Effect size } \\
\text { pretest to } \\
\text { follow-up }\end{array}$} \\
\hline & Pretest & Posttest & Follow-up & Pretest & Posttest & Follow-up & & \\
\hline Reactive aggression teacher & $3.84(0.87)$ & $3.40(0.89)$ & $3.02(0.97)$ & $3.74(0.95)$ & $3.57(0.94)$ & $3.29(0.93)$ & $0.28 *$ & $0.40 * *$ \\
\hline Proactive aggression teacher & $2.46(0.89)$ & $2.09(0.98)$ & $1.93(0.87)$ & $2.17(0.89)$ & $2.08(0.92)$ & $1.92(0.96)$ & 0.30 & 0.31 \\
\hline Aggressive behaviour teacher & $0.78(0.38)$ & $0.68(0.41)$ & $0.55(0.38)$ & $0.76(0.34)$ & $0.79(0.45)$ & $0.66(0.40)$ & $0.33 * *$ & $0.34 * *$ \\
\hline Delinquent behaviour teacher & $0.38(0.25)$ & $0.36(0.32)$ & $0.28(0.23)$ & $0.45(0.27)$ & $0.43(0.29)$ & $0.34(0.24)$ & 0.00 & -0.04 \\
\hline Reactive aggression child & $3.03(0.88)$ & $2.80(0.81)$ & $2.95(0.90)$ & $3.03(0.81)$ & $3.00(0.87)$ & $2.95(0.82)$ & $0.21 *$ & 0.00 \\
\hline Proactive aggression child & $1.48(0.70)$ & $1.35(0.54)$ & $1.37(0.60)$ & $1.61(0.80)$ & $1.62(0.84)$ & $1.47(0.65)$ & $0.22 * *$ & -0.04 \\
\hline
\end{tabular}

Note:

$* p<.05$.

$* * p<.01$.

for each personality trait as potential moderator. Results indicated that the interaction between conscientiousness and intervention status significantly predicted teacher reported proactive aggression $(F(3,263)=3.48, p=.02)$ and delinquent behaviour $(F(3,263)=2.95, p=.03)$ at posttest. Moreover, conscientiousness $\times$ intervention status predicted child reported proactive aggression $(F(3,263)=2.92, p=.05)$. Post-hoc analyses revealed that the strongest intervention effects on teacher reported proactive aggression $(d=0.43)$ and delinquent behaviour $(d=0.32)$, and child reported proactive aggression $(d=0.46)$ were found for children who had less extreme scores on conscientiousness. Child reported reactive aggression at posttest was predicted by extraversion intervention status $(F(3,263)=5.13, p=.00)$. Post-hoc analyses revealed that less extraverted children showed the strongest intervention effects on reactive aggression $(d=0.88)$. No other significant interactions between personality and intervention status were found at posttest.

At follow-up, effects on child reported reactive aggression $(F(3,263)=3.28, p=.02)$, teacher reported reactive aggression $(F(3,263)=5.60, p<.001)$ and proactive aggression $(F(3,263)=3.04, p=.03)$ were moderated by personality trait extraversion. Marginally significant effects of intervention status $\times$ extraversion were found for teacher reported aggressive behaviour $(F(3,263)=2.38, p=.07)$ at follow-up. Post-hoc analyses revealed that the strongest intervention effects on child $(d=1.02)$ and teacher reported reactive aggres$\operatorname{sion}(d=0.85)$, teacher reported proactive aggression $(d=0.60$. $)$ and teacher reported aggressive behaviour $(d=0.68)$ were found for low extraverted children. These results suggested that maintenance of beneficial effects at long-term sustained, for less extraverted children. Conscientiousness did not moderate any of the outcomes at follow-up.

The three other personality traits, benevolence, emotional stability and imagination, did not moderate any of the outcomes at posttest or follow-up.

\section{DISCUSSION}

The present study expanded previous intervention studies that examined moderators of intervention effects by focusing on moderation by child personality measured with the Big Five instrument. We examined which children benefitted from an indicated intervention for externalising problem behaviour, immediately after the intervention and at follow-up. Specific child personality traits appeared to influence intervention effects.

Short-term intervention effects were moderated by personality trait conscientiousness. This finding enriches findings from the effect study (Stoltz et al., 2012), because it gives indications which children might profit more from the Stay Cool Kids intervention (Hinshaw, 2007). Conscientious children are characterised as being organised and planful. Also, they are motivated to fulfil tasks and are goal-directed (Mervielde \& De Fruyt, 2002). The strongest intervention effects were found for those children who scored less extreme on conscientiousness. For highly conscientious children, aggressive behaviour declined in both the intervention and the control group. However, for low conscientious children aggressive behaviour remained stable after the intervention. These findings suggest that these children are hard to treat with a preventive intervention and that extra therapeutic effort may be needed. It is noteworthy that moderated effects were found on those teacher reported outcomes where no intervention effects were found for the total group (proactive aggression, delinquency). Proactive aggression and delinquency may be less sensitive to change, because these types of aggression are used as a mean to achieve certain rewards (Dodge, 1991). When children believe that their aggressive behaviour is functional in obtaining desired outcomes it might be more difficult to convince them to change their strategies into more prosocial behaviour. A specific subgroup of less extreme conscientious children responds better to the intervention, in terms of proactive aggression and delinquency.

Both short-term and follow-up intervention effects were moderated by child extraversion. This indicates that among children indicated because of externalising behaviour problems, those who are highly extraverted are at risk for poorer treatment outcomes. Teacher-reported effects on reactive aggression and aggressive behaviour were sustained for all children in fifth grade, but low extraverted children showed the strongest intervention effects. Moreover, only for low extraverted children maintenance of intervention effects were found on child reported reactive aggression and teacher reported proactive aggression. Low extraverted children are characterised by lower expressivity, higher shyness and display less activity (De Pauw \& Mervielde, 2010). Perhaps, these children are less likely to fall back into old behaviours, 
are less sensitive to peer pressure, have more inhibitory control and are more sensitive to the consequences of their behaviour and correction of behaviour (e.g. Matthys, Vanderschuren, \& Schutter, 2012). The risk for poorer treatment outcomes associated with extraverted traits, may be partly due to the relationship between extraverted traits, elevated activity levels and less inhibited behaviour. For these children, it may be more difficult to implement newly learned behaviour. Especially for these children, a booster may help further benefits from the intervention at followup (Tolan, Gorman-Smith, Henry, \& Schoeny, 2009). Another explanation is that more organised and planful children and the less extraverted (less activity, less impulsive) children benefited most from the intervention, because their problem behaviour is less ingrained and more of a reaction to current life stressors, rather than being personalityrelated. For less conscientious and more extraverted children, problem behaviour may be more personality-related.

It is encouraging that effects of this implemented intervention on (reactive and proactive) aggression sustained at follow-up for at least a part of the children, although effect sizes are small to moderate. However, even small effect sizes can be of practical significance, because a small reduction in aggressive behaviour may break a vicious cycle (McCartney \& Rosenthal, 2000). With this intervention, the developmental trajectory towards more serious behaviour problems can possibly be interrupted. However, for highly extraverted and low conscientious children, it is necessary to develop a more intensive individualised intervention to prevent them from developing life-course persistent conduct problems.

On the basis of associations with externalising behaviour (e.g. Prinzie et al., 2010), we expected benevolence, besides conscientiousness and extraversion, to be related to intervention outcomes. However, intervention effects were not moderated by level of benevolence. Benevolent children are friendly, easy-going and compliant (John et al., 1994). This result suggests that the programme is as effective with less kind, empathic and friendly children, perhaps because of the individual targeted nature of the programme.

\section{Strengths, limitations and directions for future research}

The present study had several strengths. First, it offers the potential to contribute to the relatively understudied area of investigating theoretically grounded moderators in effectiveness studies (Weersing \& Weisz, 2002). Moreover, to our knowledge, this is the first study that included child personality as moderator in an effectiveness trial, using a randomised controlled trial design, well-established measures and three waves of data collection. This study can contribute to our knowledge about the role of personality in children's development and also to clinical practice by showing personality to be a moderator of intervention effectiveness. Finally, we were able to avoid the problem of method overlap by using multiple informants for reporting on child personality and problem behaviour.

However, several methodological limitations warrant caution in interpretation of results. First, it is worth noting that the unit of analyses (individual level) did not match the unit of randomisation (school level) in this study, which might have increased the risk of false-positive finding (Stice, Shaw, Bohon, Marti, \& Rohde, 2009). The present design permitted us to study actual effects of an intervention implemented in routine school practice. Allowing each school to participate both in control and intervention conditions and blockwise randomisation made it practically feasible for schools to participate. This would not have been possible with a traditional individual randomisation to either control or intervention condition because ethical issues concerning assignment of individual children in the same classroom to different conditions and lack of motivation to participate in the control condition would have prevented schools, teachers and parents from participating in the study. Moreover, the present design prevented biases due to school factors by delivering intervention and control conditions in the very same schools. In addition, results are based on child and teacher reported data using questionnaires. Using a multi-method strategy, which includes observational measures in addition to questionnaires, would increase reliability and generalizability of results. Even though our study includes follow-up measurements at half-year after treatment termination, future research should focus on longer-term follow-up.

Notwithstanding these limitations, the current study has some significant implications for research and clinical practice. For outcome research, it is essential to focus not just on efficacy and effectiveness of interventions but to include child personality as potential moderator in future studies. Because the current study indeed showed that personality influences intervention effects, other intervention studies should investigate which subgroups of children, with specific personality traits, respond to the intervention and for which subgroups other forms of help or adaptations of the programme are needed. Assessing factors that predict and moderate follow-up effects can help identify those children who are at risk to continue with problem behaviour. Adapted booster intervention can be developed for these children.

For clinical practice, it is important, first, to know that a school-based individual preventive intervention can help children to develop less aggressive behaviour both immediate after the intervention as after six months, when they move to the next grade. Schools are promising locations for interventions because children can be reached in a systematic and efficient way. Offering prevention activities in a school setting may make treatment more acceptable (Catron \& Weiss, 1994) and increases the likelihood of generalisation and maintenance of treatment effects to the natural environment (Evans, Langberg, \& Williams, 2003). Although findings should be considered tentative, until replicated with other intervention study samples, they raise the question of how interventions might be adapted to target high extraverted and low conscientious children more effectively. Perhaps these children need a longer, more intensive individual targeted intervention. Knowledge of different child characteristics can lead to personalised mental health care or modular protocols, by adapting programmes to the child's specific needs, which in turn can produce stronger intervention effects (Chorpita, Daleiden, \& Weisz, 2005; Frick \& White, 2008). 


\section{ACKNOWLEDGEMENTS}

This work was supported by the Central Committee on Research inv. Human Subjects: NL19535.041.08 and ZON-MW, The Netherlands Organisation for Health Research and Development: 157001006.

\section{REFERENCES}

Achenbach, T. M. (1991). Manual for the Teacher Report Form and 1991 profiles. Burlington: University of Vermont, Department of Psychiatry.

Baraldi, A. N., \& Enders, C. K. (2010). An introduction to modern missing data analyses. Journal of School Psychology, 48, 5-37. doi: 10.1016/j.jsp.2009.10.001

Baron, R. M., \& Kenny, D. A. (1986). The moderator-mediator variable distinction in social psychological research: Conceptual, strategic, and statistical considerations. Journal of Personality and Social Psychology, 51, 1173-1182. doi: 0022-3514/86/\$00.75

Beauchaine, T. P., Webster-Stratton, C., \& Reid, M. J. (2005). Mediators, moderators, and predictors of 1-year outcomes among children treated for early-onset conduct problems: A latent growth curve analysis. Journal of Consulting and Clinical Psychology, 73, 371-388. doi: 10.1037/0022-006X.73.3.371

Belsky, J. (2005). Differential susceptibility to rearing influence: An evolutionary hypothesis and some evidence. In B. J. Ellis, \& D. F. Bjorklund (Eds), Origins of the social mind: Evolutionary psychology and child development (pp. 139-163). New York: Guilford Publications.

Broidy, L. M., Tremblay, R. E., Brame, B., Fergusson, F., Horwood, J. L., Laird, R.,... Vitaro, F. (2003). Developmental trajectories of childhood disruptive behaviours and adolescent delinquency: A six-site, cross-national study. Developmental Psychology, 39, 222-245.

Caspi, A., \& Shiner, R. (2006). Personality development. In W. Damon, \& N. Eisenberg (Eds), Handbook of child psychology, volume 3: Social, emotional, and personality development (pp. 300-365). New York: Wiley.

Catron, T., \& Weiss, B. (1994). The Vanderbilt school-based counselling program. Journal of Emotional and Behavioral Disorders, 2, 247-253. doi: 10.1177/106342669400200407

Chorpita, B. F., Daleiden, E. L., \& Weisz, J. R. (2005). Modularity in the design and application of therapeutic intervention. Applied and Preventive Psychology, 11, 141-156. doi: 10.1016/j.appsy.2005.05.002

Cohen, J. (1988). Statistical power analysis for the behavioral sciences. Hillsdale, NJ: Erlbaum.

Conrod, P. J., Castellanos, N., \& Mackie, C. (2008). Personalitytargeted interventions delay the growth of adolescent drinking and binge drinking. Journal of Child Psychology and Psychiatry, 49, 181-190. doi:10.1111/j.1469-7610.2007.01826.x

Conrod, P. J., Castellanos-Ryan, N., \& Strang, J. (2010). Brief, personality-targeted coping skills interventions and survival as a non-drug user over a 2-year period during adolescence. Archives of General Psychiatry, 67, 85-93.

Conrod, P. J., Stewart, S. H., Comeau, N., \& Maclean, A. M. (2006). Efficacy of cognitive-behavioral interventions targeting personality risk factors for youth alcohol misuse. Journal of Clinical Child and Adolescent Psychology, 35, 550-563. doi:10.1207/s15374424jccp3504_6

Crick, N. R., \& Dodge, K. A. (1994). A review and reformulation of social information-processing mechanisms in children's social adjustment. Psychological Bulletin, 115, 74-101. doi: 10.1037/0033-2909.115.1.74

De Castro, B. O., Merk, W., Koops, W., Veerman, J. W., \& Bosch, J. D. (2005). Emotions in social information processing and their relations with reactive and proactive aggression in referred aggressive boys. Journal of Clinical Child and Adolescent Psychology, 34, 105-116. doi: 10.1207/s15374424jccp3401_10
De Haan, A. D., Prinzie, P., \& Deković, M. (2010). How and why children change in aggression and delinquency from childhood to adolescence: Moderation of overreactive parenting by child personality. Journal of Child Psychology and Psychiatry, 51, 725-733. doi: 10.1111/j.1469-7610.2009.02192.x

De Pauw, S. S. W., \& Mervielde, I. (2010). Temperament, personality and developmental psychopathology: A review based on the conceptual dimensions underlying childhood traits. Child Psychiatry and Human Development, 41, 313-329. doi: 10.1007/s10578-009-0171-8

Dodge, K. A. (1991). The structure and function of reactive and proactive aggression. In D. Pepler, \& K. H. Rubin (Eds), The development and treatment of childhood aggression (pp. 201-218). Hillsdale, NJ: Lawrence Erlbaum Associated, Inc.

Dodge, K. A., \& Coie, J. D. (1987). Social information processing factors in reactive and proactive aggression in children's peer groups. Journal of Personality and Social Psychology, 53, 1146-1158. doi: 10.1037/0022-3514.53.6.1146

Evans, S. W., Langberg, J., \& Williams, J. (2003). Achieving generalization in school-based mental health. In M. D. Weist, S. W. Evans, \& N. A. Lever (Eds), Handbook of school mental health: Advancing practice and research (pp, 335-348). New York: Kluwer Academic/Plenum Publishers.

Frick, P. J. (2004). Integrating research on temperament and childhood psychopathology: Its pitfalls and promise. Journal of Clinical Child and Adolescent Psychology, 33, 2-7. doi: 10.1207/S15374424JCCP3301_1

Frick, P. J., \& White, S. F. (2008). The importance of callousunemotional traits for developmental models of aggressive and antisocial behavior. Journal of Child Psychology and Psychiatry, 49, 359-375. doi: 10.1111/j.1469-7610.2007.01862.x

Gardner, F., Hutchings, J., Bywater, T., \& Whitaker, C. (2010). Who benefits and how does it work? Moderators and mediators of outcome in an effectiveness trial of a parenting intervention. Journal of Clinical Child and Adolescent Psychology, 39, 568-580. doi: 10.1080/15374416.2010.486315

Goldberg, L. R. (2001). Analyses of Digman's child-personality data: Derivation of Big-Five factor scores from each of six samples. Journal of Personality, 69, 709-743. doi: 10.1111/ 1467-6494.695161

Hawes, D. J., \& Dadds, M. R. (2005). The treatment of conduct problems in children with callous-unemotional traits. Journal of Consulting and Clinical Psychology, 73, 737-741. doi: 10.1037/0022-006X.73.4.737

Hendrickx, M., Crombez, G., Roeyers, H., \& Orobio de Castro, B. (2003). Psychometrische evaluatie van de Nederlandstalige versie van de Agressie Beoordelingsschaal van Dodge en Coie (1987) [Psychometric evaluation of the Dutch version of Dodge \& Coie's (1987) Aggression Rating Scale]. Tijdschrift voor Gedragstherapie, 36, 33-43.

Hinshaw, S. P. (2002). Intervention research, theoretical mechanisms, and causal processes related to externalizing behavior patterns. Development and Psychopathology, 14, 789-818. doi: 10.1017/ S0954579402004078

Hinshaw, S. P. (2007). Moderators and mediators of treatment outcome for youth with ADHD: Understanding for whom and how interventions work. Journal of Pediatric Psychology, 32, 664-675. doi: 10.1093/jpepsy/js1055

John, O. P., Caspi, A., Robins, R. W., Moffitt, T. E., \& StouthamerLoeber, M. (1994). The 'little five': Exploring the nomological network of the five-factor model of personality in adolescent boys. Child Development, 65, 160-178. doi: 0009-3920/94/6501-0008\$01.00

Jöreskog, K., Sörbom, D. (1996). LISREL 8. User's reference guide. Chicago: Scientific Software International.

Kazdin, A. E. (2007). Mediators and mechanisms of change in psychotherapy research. Annual Review of Clinical Psychology, 3, 1-27. doi: 10.1146/annurev.clinpsy.3.022806.091432

Kellam, S. G., \& Rebok, G. W. (1992). Building developmental and etiological theory through epidemiologically based preventive intervention trials. In J. McCord, \& R. E. Tremblay (Eds), 
Preventing antisocial behavior: Intervention from birth through adolescence (pp. 162-195). New York: Guilford.

Kraemer, H. C., Wilson, T., Fairburn, C. G., \& Agras, W. S. (2002). Mediators and moderators of treatment effects in randomized clinical trials. Archives of General Psychiatry, 59, 877-883.

La Greca, A. M., Silverman, W. K., \& Lochman, J. E. (2009). Moving beyond efficacy and effectiveness in child and adolescent intervention research. Journal of Consulting and Clinical Psychology, 77, 373-382. doi: 10.1037/a0015954

Lemerise, E. A., \& Arsenio, W. F. (2000). An integrated model of emotion processes and cognition in social information processing. Child Development, 71, 107-118. doi: 10.1111/ 1467-8624.00124

Lipsey, M. W., \& Wilson, D. B. (2001). Practical meta-analysis. Thousand Oaks, CA: Sage.

Manders, W., Scholte, R. H. J., Janssens, J. M. A. M., \& De Bruyn, E. E. J. (2006). Adolescent personality, problem behaviour and the quality of the parent-adolescent relationship. European Journal of Personality, 20, 237-254. doi: 10.1002/per.574

Matthys, W., Vanderschuren, L. J. M. J., \& Schutter, D. J. L. G. (2012). The neurobiology of oppositional defiant disorder and conduct disorder: Altered functioning in three mental domains. Development and Psychopathology, in press.

McCart, M. R., Priester, P. E., Davies, W. B., \& Azen, R. (2006). Differential effectiveness of behavioral parent training and cognitive-behavioral therapy for antisocial youth: A metaanalysis. Journal of Abnormal Child Psychology, 34, 527-543. doi: 10.1007/s10802-006-9031-1

McCartney, K., \& Rosenthal, R. (2000). Effect size, practical importance, and social policy for children. Child Development, 71, 173-180. doi: 10.1111/1467-8624.00131

McCrae, R. R., \& Costa, P. T. (1999). A five-factor theory of personality. In L. A. Pervin, \& O. P. John (Eds), Handbook of personality: Theory and research (pp. 139-153). New York: Guilford Press.

Mervielde, I., \& De Fruyt, F. (1999). Construction of the Hierarchical Personality Inventory for Children. In I. Mervielde, I. J. Deary, F. De Fruyt, \& F. Ostendorf (Eds), Personality psychology in Europe (Vol 7, pp. 107-127). Tilburg: Tilburg University Press.

Mervielde, I., \& De Fruyt, F. (2002). Assessing children's traits with the Hierarchical Personality Inventory for Children. In B. De Raad, \& Y. M. Perugini (Eds), Big Five assessment (pp. 129-146). Seattle, WA: Hogrefe and Huber.

Miller, J. D., \& Lynam, D. (2001). Structural models of personality and their relation to antisocial behavior: A meta-analytic review. Criminology, 39, 765-798. doi: 10.1111/j.1745-9125.2001. tb00940.x

Muthén, B. O. (2000). Methodological issues in random coefficient growth modeling using a latent variable framework: Application to the development of heavy drinking. In J. Rose, L. Chassin, C. Presson, \& J. Sherman (Eds), Multivariate applications in substance use research: New methods for new questions (pp. 113-140). Hillsdale, NJ: Erlbaum.

Prinzie, P., \& Deković, M. (2008). Continuity and change of childhood personality characteristics through the lens of teachers. Personality and Individual Differences, 45, 82-88. doi: 10.1016/j. paid.2008.03.002
Prinzie, P., Onghena, P., Hellinckx, W., Grietens, H., Ghesquiére, P., \& Colpin, H. (2003). The additive and interactive effects of parenting and children's personality on externalizing behaviour. European Journal of Personality, 17, 95-117. doi: 0.1002/per.467

Prinzie, P., van der Sluis, C. M., De Haan, A., \& Deković, M. (2010). The mediational role of parenting on the longitudinal relation between child personality and externalizing behavior. Journal of Personality, 78, 1301-1323. doi: 10.1111/j.1467-6494.2010.00651.x

Shiner, R. L., \& Caspi, A. (2003). Personality differences in childhood and adolescence: Measurement, development and consequences. Journal of Child Psychology and Psychiatry, 44, 2-32. doi: 10.1111/1469-7610.00101

Stice, E., Shaw, H., Bohon, C., Marti, C. N., \& Rohde, P. (2009). A meta-analytic review of depression prevention programs for children and adolescents: Factors that predict magnitude of intervention effects. Journal of Consulting and Clinical Psychology, 77, 486-503. doi:10.1037/a0015168

Stoltz, S., van Londen, M., Deković, M., De Castro, B. O., Prinzie, P., \& Lochman, J. E. (2012). The effectiveness of 'Stay Cool Kids': An individual preventive intervention for children with aggressive behavior at elementary schools. Behavioural and Cognitive Psychotherapy, in press.

Tackett, J. L. (2006). Evaluating models of the personalitypsychopathology relationship in children and adolescents. Clinical Psychology Review, 26, 584-599. doi: 10.1016/j.cpr. 2006.04.003

Tolan, P. H., Gorman-Smith, D., Henry, D., \& Schoeny, M. (2009). The benefits of booster interventions: Evidence from a familyfocused prevention program. Prevention Science, 10, 287-297. doi: 10.1007/s11121-009-0139-8

Tremblay, R. E. (2006). Prevention of youth violence: Why not start at the beginning? Journal of Abnormal Child Psychology, 34, 481-487. doi: 10.1007/s10802-006-9038-7

Van den Akker, A. L., Deković, M., \& Prinzie, P. (2010). Transitioning to adolescence: How changes in child personality and overreactive parenting predict adolescent adjustment problems. Development and Psychopathology, 22, 151-163. doi: 10.1017/S0954579409990320

Verhulst, F. C., van der Ende, J., \& Koot, H. M. (1997). Handleiding voor de Teacher Report Form (TRF): Nederlandse versie [Manual for the Teacher Report Form (TRF): Dutch version]. Rotterdam, The Netherlands: Afdeling Kinder en Jeugdpsychiatrie, Sophia Kinderziekenhuis/Academisch Ziekenhuis Rotterdam/Erasmus Universiteit Rotterdam.

Watt, M., Stewart, S., Birch, C., \& Bernier, D. (2006). Brief CBT for high anxiety sensitivity decreases drinking problems, relief alcohol outcome expectancies, and conformity drinking motives: Evidence from a randomized controlled trial. Journal of Mental Health, 15, 683-695. doi: 10.1080/09638230600998938

Weersing, R. V., \& Weisz, J. R. (2002). Mechanisms of action in youth psychotherapy. Journal of Child Psychology and Psychiatry, 43, 3-29. doi: 10.1111/1469-7610.00002

Wilson, S. J., \& Lipsey, M. W. (2007). School-based interventions for aggressive and disruptive behavior: Update of a meta-analysis. American Journal of Preventive Medicine, 33, 130-143. doi: 10.1016/j.amepre.2007.04.011 